\title{
High throughput in-silico screening against flexible protein receptors
}

\author{
Horacio Pérez-Sánchez ${ }^{1 *}$, Bernhard Fischer ${ }^{1}$, Daria Kokh², Holger Merlitz¹, Wolfgang Wenzel ${ }^{1}$ \\ From 5th German Conference on Cheminformatics: 23. CIC-Workshop \\ Goslar, Germany. 8-10 November 2009
}

Based on the stochastic tunneling method (STUN) [1] we have developed FlexScreen [2], a novel strategy for high-throughput in-silico screening of large ligand databases. Each ligand of the database is docked against the receptor using an all-atom representation of both ligand and receptor. The ligands with the best evaluated affinity are selected as lead candidates for drug development. Using the thymidine kinase inhibitors as a prototypical example we documented [3] the shortcomings of rigid receptor screens in a realistic system. We demonstrate a gain in both overall binding energy and overall rank of the known substrates when two screens with a rigid and flexible (up to 15 sidechain dihedral angles) receptor are compared. We note that the STUN suffers only a comparatively small loss of efficiency when an increasing number of receptor degrees of freedom is considered. FlexScreen thus offers a viable compromise [4] between docking flexibility and computational efficiency to perform fully automated database screens on hundreds of thousands of ligands. We also investigate enrichment rates [5] of rigid, soft and flexible receptor models [6] for 12 diverse receptors using libraries containing up to 13000 molecules. A flexible sidechain model with flexible dihedral angles for up to 12 aminoacids increased both binding propensity and enrichment rates: EF_1 values increased by $35 \%$ on average with respect to rigid-docking (3-8 flexible sidechains). This methodology will be soon available for the Cell processor and Pipeline Pilot.

\footnotetext{
Author details

${ }^{1}$ Institut für Nanotechnologie, Forschungszentrum Karlsruhe, Postfach 3640, 76021 Karlsruhe, Germany. ${ }^{2}$ Wuppertal, Germany.
}

Published: 4 May 2010

Institut für Nanotechnologie, Forschungszentrum Karlsruhe, Postfach 3640, 76021 Karlsruhe, Germany

\section{References}

1. Wenzel W, Hamacher K: Stochastic tunneling approach for global minimization of complex potential energy landscapes. Physical Review Letters 1999, 82(15):3003-3007.

2. Merlitz H, Burghardt B, Wenzel W: Application of the stochastic tunneling method to high throughput database screening. Chemical Physics Letters 2003, 370(1-2):68-73

3. Merlitz $H$, Burghardt $B$, Wenzel W: Impact of receptor conformation on in silico screening performance. Chemical Physics Letters 2004, 390(4-6):500-505.

4. Fischer B, et al: Accuracy of binding mode prediction with a cascadic stochastic tunneling method. Proteins-Structure Function and Bioinformatics 2007, 68(1):195-204.

5. Kokh DB, Wenzel WG: Flexible side chain models improve enrichment rates in in silico screening. Journal of Medicinal Chemistry 2008, 51(19):5919-5931.

6. Fischer B, Fukuzawa K, Wenzel W: Receptor-specific scoring functions derived from quantum chemical models improve affinity estimates for in-silico drug discovery. Proteins-Structure Function and Bioinformatics 2008, 70(4):1264-1273

doi:10.1186/1758-2946-2-S1-P23

Cite this article as: Pérez-Sánchez et al:: High throughput in-silico screening against flexible protein receptors. Journal of Cheminformatics 2010 2(Suppl 1):P23.

\section{Publish with ChemistryCentral and every scientist can read your work free of charge \\ "Open access provides opportunities to our colleagues in other parts of the globe, by allowing anyone to view the content free of charge." W. Jeffery Hurst, The Hershey Company. \\ - available free of charge to the entire scientific community \\ - peer reviewed and published immediately upon acceptance \\ - cited in PubMed and archived on PubMed Central \\ - yours - you keep the copyright \\ Submit your manuscript here: \\ http://www.chemistrycentral.com/manuscript/ Chemistry Central}

